\title{
Primary Antituberculosis Drug Resistance at Turkish Military Chest Diseases Hospital in Istanbul
}

\author{
Zafer Kartaloglu Erkan Bozkanat Hakan Ozturkeri Oguzhan Okutan \\ Ahmet Ilvan
}

Gata Camlica Chest Diseases Hospital, Istanbul, Turkey

\section{Key Words}

Tuberculosis · Primary drug resistance - Turkey

\begin{abstract}
Objective: The aim of this study was to investigate the prevalence of primary drug resistance to tuberculosis. Methods: We evaluated the clinical data, radiological features and sputum samples from 365 newly diagnosed patients with a positive culture of pulmonary tuberculosis at the Turkish Military Chest Diseases Hospital, Istanbul, Turkey. No patients had taken antituberculosis drugs previously. The Bactec method was used to perform drug susceptibility testing for isoniazid, rifampicin, ethambutol, and streptomycin. Results: Primary resistance to one or more drugs was detected in 87 (23.8\%) patients; resistance to isoniazid was most common (54 patients) followed by resistance to ethambutol $(n=39)$, rifampicin $(n=11)$, and streptomycin $(n=9)$. One-drug resistance was detected in 69 patients; two-drug resistance in 11 , three-drug resistance in 6 , and four-drug resistance in 1 . Multidrug resistance (resistance to at least isoniazid and rifampicin) was detected in 10 patients. In logistic-regression analysis, primary drug resistance was associated with radiological advanced tuberculosis $(p<0.001)$. Conclusion: Primary resistance to one or more drugs used in treating tuberculosis is relatively high. It is necessary to regularly screen for and treat drug resistance among those who live in close quarters, such
\end{abstract}

as army barracks, school dormitories and prisons. Regular surveillance of drug sensitivity patterns should be maintained to determine appropriate alternate drug regimens and detect the spread of resistant stains in the population.

Copyright @2002S. Karger AG, Basel

\section{Introduction}

Tuberculosis (TB) is one of the oldest known diseases in the world. It has been recognized for 116 years and effective chemotherapeutic regimens have existed for 54 years. Though it had remained a challenge for developing countries, industrialized countries had partly solved the TB problem. However, partly due to AIDS and mass population movements, TB has again emerged as a serious global public health issue. A case of pulmonary TB can infect 2-3 individuals in developed countries and 3-5 individuals in developing countries before a diagnosis is made [1].

The emergence of drug-resistant tuberculosis (DRTB), especially multidrug-resistant tuberculosis (MDRTB), poses a major threat to the control and prevention of TB [2-4]. It is known that the rate of primary resistance is approximately $5 \%$ or less in effective national programs, and $15 \%$ or more in newly implemented programs [5]. Previous reports from Turkey have shown high levels of primary and secondary drug resistance [6-8]. Because of this high degree of drug resistance, TB is easily transmit-

\begin{tabular}{ll}
\hline KARGER & ( ) 2002 S. Karger AG, Basel \\
$1011-7571 / 02 / 0114-0202 \$ 18.50 / 0$ \\
$\begin{array}{l}\text { Fax +4161306 1234 } \\
\begin{array}{l}\text { E-Mail karger@karger.ch } \\
\text { www.karger.com }\end{array}\end{array}$ & $\begin{array}{l}\text { Accessible online at: } \\
\text { www.karger.com/mpp }\end{array}$
\end{tabular}

Zafer Kartaloglu, Assoc. Prof.
Gata Camlica Chest Diseases Hospital Acibadem/Uskudar
TR-81020 Istanbul (Turkey)
Tel. +90216 3257250, Fax +90 2163257257
E-Mail zkartaloglu@hotmail.com 
ted within populations in close contact, such as the military. For this reason, we studied the prevalence of primary DR-TB and MDR-TB among military personnel and their dependents attending the Chest Diseases Hospital in Istanbul, Turkey.

\section{Subjects and Methods}

\section{Subjects}

Three hundred and sixty-five patients that were hospitalized in the Chest Diseases Clinic, Gata Camlica Chest Diseases Hospital between January 1999 and January 2000 with a diagnosis of pulmonary TB were included in the study. None of the patients had taken antituberculosis drugs previously.

Physical examination, routine hematological assessments and a purified protein-derived (PPD) skin test were performed for all cases. A PPD reaction of $\geq 10 \mathrm{~mm}$ of induration was classified as positive. The ELISA test for HIV antibodies (Abbott, HIV 1-2, USA) was also done. Pulmonary TB was radiologically classified as minimal, moderately advanced or far advanced [9]. Minimal lesions included those of slight to moderate density but which did not contain demonstrable cavitation. They may have involved a small part of one or both lungs, but the total extent regardless of distribution did not exceed the volume of lung on one side present above the second chondrosternal junction and the spine of the fourth or the body of the fifth thoracic vertebra. Moderately advanced lesions might have been present in one or both lungs, but the total extent did not exceed the following limits: disseminated lesions of slight to moderate density which may have extended throughout the total volume of one lung or the equivalent in both lungs; dense and confluent lesions limited in extent to one third the volume of one lung; total diameter of cavitation, if present, was less than $4 \mathrm{~cm}$. Far advanced lesions were those more extensive than 'moderately advanced'.

Our hospital serves as a center for military hospitals in western Turkey. Each year, approximately 2,500-3,000 patients are hospitalized with a diagnosis of any respiratory disease, including 1,0001,200 cases of TB. It is compulsory to report cases of TB to the Tuberculosis Fighting Outpatient Clinic, Health Ministry, which launches investigations and provides necessary drugs to the patients. We use standard chemotherapy regimen and WHO guidelines for management of DR-TB [5].

\section{Preparation of the Material}

All sputum samples sent to the TB laboratory underwent decontamination and neutralization procedures with a $2 \% \mathrm{NaOH}$ solution within $2 \mathrm{~h}$, after which they were centrifuged with $3,000 \mathrm{rpm}$ for 20 min and the supernatant discarded. The sediment was divided into two parts: one was stained using the Ziehl-Neelsen method and the smear examined. The other portion for culture was incubated with a Bactec 12B culture medium (Bactec 460, Becton Dickinson, Sparks, Md., USA) and left to grow. It was checked every 2 days during the 1 st week and weekly afterwards. The final bacterial growth was determined at the end of the 6 th week.

\section{Identification and Drug Susceptibility Testing}

A nitro alpha acetylamino beta hydroxypropiophenone (NAP) test was used for the identification of mycobacterium. The isolate
Table 1. General features of patients with primary drug resistance

\begin{tabular}{lcc}
\hline Features & $\begin{array}{l}\text { Study } \\
\text { population }\end{array}$ & $\begin{array}{c}\text { Any drug } \\
\text { resistance }\end{array}$ \\
\hline Sex & & \\
$\quad$ Female & 13 & 4 \\
$\quad$ Male & 352 & 83 \\
Age & & \\
$\quad<25$ & 253 & 63 \\
$25-44$ & 84 & 17 \\
$\quad 45-64$ & 19 & 5 \\
$\quad \geq 65$ & 9 & 2 \\
Nonsmoker & 127 & 30 \\
Smoker & 238 & 57 \\
PPD test & & 6 \\
$\quad$ 0-9 mm & 61 & 81 \\
$\quad \geq 10$ mm & 304 & 15 \\
Chest X-ray & & 57 \\
$\quad$ Minimal & 125 & 15 \\
$\quad$ Moderately advanced & 191 & 87 \\
$\quad$ Far advanced & 49 & 0 \\
HIV & & \\
$\quad$ Negative & 365 & \\
$\quad$ Positive & 0 & \\
\hline
\end{tabular}

was identified as Myocobacterium tuberculosis complex when the growth of mycobacterium was inhibited in the presence of NAP [10].

The antimicrobial susceptibility testing of $M$. tuberculosis complex isolates was performed by the indirect radiometric proportion method (Bactec). Antimicrobial agents tested against $M$. tuberculosis complex isolates and final drug concentrations with the Bactec 12B medium were as follows: isoniazid $0.1 \mu \mathrm{g} / \mathrm{ml}$, rifampicin $2.0 \mu \mathrm{g} / \mathrm{ml}$, streptomycin $2.0 \mu \mathrm{g} / \mathrm{ml}$, and ethambutol $2.5 \mu \mathrm{g} / \mathrm{ml}$ [10].

\section{Statistical Analysis}

All data are reported as mean \pm SD. Multivariate logistic regression was performed to calculate odds ratios and $95 \%$ confidence intervals for risk quantification (sex, age, smoking, radiological appearance, PPD). All risk factors are presented as dichotomous variables. A value of $p<0.05$ was considered significant for drug resistance to any of the four first-line drugs.

\section{Results}

\section{Characteristics of Patients}

Primary resistance to one or more drugs was detected in $87(23.8 \%)$ patients: 83 were male and 4 were female, with a mean age of $25.5 \pm 9.9$ years (range, 19-71). Twelve patients with primary drug resistance were lost contacts and could not be followed up. Follow-up was possible for 75 patients $(86.2 \%)$, of whom 73 (83.9\%) recovered and $2(2.3 \%)$ were unsuccessfully treated. Fifty-seven 


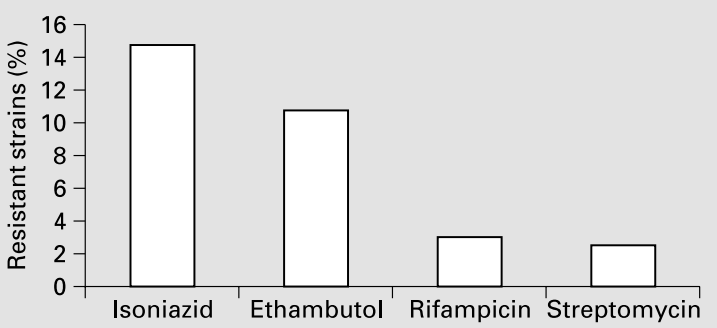

Fig. 1. Antituberculosis drug resistance of cases.

Table 2. Patterns of drug resistance among 365 cases with primary M. tuberculosis infection

\begin{tabular}{lcc}
\hline \multirow{2}{*}{ Isolates' response to drugs } & Isolates \\
\cline { 3 - 3 } & $\mathrm{n}$ & $\%$ \\
\hline Resistance to one or more drugs & 87 & 23.8 \\
Resistance to one drug only & 69 & 18.9 \\
Isoniazid (INH) & 37 & 10.1 \\
Rifampicin (RIF) & 1 & 0.3 \\
Ethambutol (ETB) & 27 & 7.4 \\
Streptomycin (SM) & 4 & 1.1 \\
Resistance to two drugs only & 11 & 3.0 \\
INH + RIF & 3 & 0.8 \\
INH + ETB & 5 & 1.3 \\
INH + SM & 2 & 0.6 \\
SM + ETB & 1 & 0.3 \\
RIF + ETB & 0 & 0 \\
RIF + SM & 0 & 0 \\
Resistance to three drugs only & 6 & 1.6 \\
INH + RIF + ETB & 5 & 1.3 \\
INH + RIF + SM & 1 & 0.3 \\
INH + ETB + SM & 0 & 0 \\
RIF + ETB + SM & 0 & 0 \\
Resistance to all four drugs & 1 & 0.3 \\
INH + RIF + ETB + SM & 1 & 0.3 \\
\end{tabular}

cases with primary drug resistance involved cigarette smokers (65.5\%). The mean PPD measurement was 15.7 $\pm 5.6 \mathrm{~mm}$ (range, $0-25$ ); the PPD test was negative in 6 patients. Radiological examinations revealed that 72 cases were moderately or far advanced (table 1). All the patients were HIV-negative.

\section{Drug Resistance}

Resistance to a single drug was found to be most prevalent $(n=69)$ among the resistant patients. Two-drug resistance was noted in 11 patients, three-drug resistance in 6 patients, and four-drug resistance in 1 patient (table 2).
Resistance to isoniazid was most common, having been observed in $54(14.8 \%)$ patients, followed by resistance to ethambutol $39(10.7 \%)$, rifampicin in $11(3 \%)$, and streptomycin in $9(2.5 \%)$ (fig. 1). Multi-drug resistance (resistance to at least isoniazid and rifampicin) was detected in 10 patients. Six patients were cured, including 2 cases of probable cure. Two cases were considered as lost contacts, and for the other 2 cases, treatment was unsuccessful. The most important risk factor for drug resistance was radiological appearance $(\mathrm{p}<0.001)$.

\section{Discussion}

The high primary drug resistance rate is a serious health problem in Turkey, as the incidence of TB is $30 / 100,000$ [11]. The primary resistance rate has been shown to range from 16.6 to $26.6 \%[6,12]$. In this study, primary resistance was $23.8 \%$, consistent with previous reports. A number of studies have reported isoniazid as the drug with the highest rate of resistance [13-17]. However, rifampicin [18], streptomycin [19-22], or ethambutol [23] have also been reported as having the highest incidence of resistance in some countries. In Turkey, it was found that isoniazid [7] and streptomycin [6] had the highest resistance figures. The reasons for these differences among countries could be due to variations in patient characteristics, general drug use, susceptibility test (Bactec, Löwenstein, etc.) methods, and the proportion of drug concentration.

In this study, ethambutol was associated with the second highest incidence of single-drug resistance, probably because it was the most commonly used. This resistance to ethambutol is of concern to treating physicians because streptomycin is autotoxic, nephrotoxic and is not used for older patients. Equally important, although resistance to rifampicin was observed in only 1 patient, it was involved in the MDR-TB of patients (table 2).

Although primary MDR-TB is reported to have an incidence of $0-54 \%$, it is very hard to find and treat these cases [13-25]. In addition, the financial cost to treat these cases is high [26]. In this study, 10 patients had MDR-TB. Six of them were cured including two that were partially cured. Our cure rate $(60 \%)$ was close to that reported by Tahaoglu et al. [27]. The successful management of MDR-TB cases will decrease the incidence of primary multidrug resistance in the population. Application of directly observed therapy (DOT) will help decrease MDR-TB and/or DR-TB cases [28].

It has been reported that characteristics such as age $[27,29,30]$, sex [29, 30], race/ethnicity [30], and HIV 
infection $[15,20,30]$ are risk factors for drug resistance among TB patients. In this study, age, sex, smoking and PPD skin test were not considered significant risk factors for developing drug resistance. But there was a significant relationship between widespread radiological lesions on lung X-rays and drug resistance, probably because of the high number of bacilli in an advanced disease. Another probable explanation is that drug resistance is more common in cavitary lesions because they facilitate growth [31]. Another risk factor for drug resistance is bilateral disease at presentation, as reported by al Jarad et al. [32].

\section{Conclusion}

Because primary resistance to one or more drugs used in treating TB is relatively high, it is essential to regularly screen for and treat drug resistance among those who live in close quarters, such as army barracks, school dormitories and prisons. Regular surveillance of drug sensitivity patterns should be maintained to determine appropriate alternate drug regimens and detect the spread of resistant strains in the population.

\section{References}

1 Grange JM: Mycobacterial diseases in the world: Yesterday, today and tomorrow; in Radladge C, Stanford J, Grange JM (eds): The Biology of the Mycobacteria. London, Academic Press, 1989, vol 3, pp 3-36.

2 Raviglion MC, Snider DE, Kochi A: Global epidemiology of tuberculosis, morbidity and mortality of a worldwide epidemic. JAMA 1995;273:220-226.

3 Snider DE, La Montagne JR: The neglected global tuberculosis problem: A report of the 1992 World Congress on Tuberculosis. J Infect Dis 1994;169:1189-1196.

4 Joint Tuberculosis Committee of the British Thoracic Society: Chemotherapy and management of tuberculosis in the United Kingdom: Recommendations 1998. Thorax 1998;53: 536-548.

5 Guidelines for the management of drug-resistance tuberculosis. WHO/TB/96.210 (rev 1), Geneva, 1997, pp 1-47.

6 Tahaoglu K, Kizkin O, Karagoz T, Tor M, Partal M, Sadoglu T: High initial and acquired drug resistance in pulmonary tuberculosis in Turkey. Tuber Lung Dis 1994;75:324-328.

7 Bengisun JS, Karnak D, Palabiyikoglu I, Saygun N: Mycobacterium tuberculosis drug resistance in Turkey, 1976-97. Scand J Infect Dis 2000;32:507-510

8 Balci I, Dikensoy O, Bayram A, Filiz A: Drugresistant tuberculosis at the University Hospital in Gaziantep, South-eastern Turkey. J Int Med Res 2000;28:300-306.

9 Seaton A, Seaton D, Leitch AG: Crofton and Douglas's Respiratory Diseases, ed 4. Oxford, Blackwell, 1989, pp 409-410.

10 Siddiqi SH: Bactec TB System Product and Procedure Manual. Sparks, Becton-Dickinson Diagnostic Instrument System, 1995.

11 Web page of Turkish Ministry of Health. URL: http://www.verem.saglik.gov.tr

12 Cerrahoglu K, Aydilek R, Ozturkeri H, Ilvan A, Kartaloglu Z, Okutan O: Primary and secondary drug resistance of soldiers with pulmonary tuberculosis. Annu Meet Int Union against Tuberculosis and Lung Disease, Paris 1995. Tuber Lung Dis 1995; 76(suppl 2):91-92.
13 Zwolska Z, Augustynowicz-Kopec E, Klatt M: Primary and acquired drug resistance in Polish tuberculosis patients: Results of a study of national drug resistance surveillance programme. Int J Tuberc Lung Dis 2000;4:832-838.

14 Nutini S, Tortoli E, Corrado A: Multidrugresistant tuberculosis in the Florence province from 1992 to 1995. Int $\mathbf{J}$ Tuberc Lung Dis 1998;2:484-489.

15 Fujiwara PI, Cook SV, Rutherford CM, Crawford JT, Glickman SE, Kreiswirth BN, Sachdev PS, Osahan SS, Ebrahimzadeh A, Frieden TR: A continuing survey of drug-resistant tuberculosis. New York City, April 1994. Arch Intern Med 1997;157:531-536.

16 Antunes ML, Aleixo-Dias J, Antunes AF, Pereira MF, Raymundo E, Rodrigues MF: Antituberculosis drug resistance in Portugal. Int $\mathbf{J}$ Tuberc Lung Dis 2000;4:223-231.

17 Mertz BL, Douce RW, Brito N: Anti-tuberculosis drug resistance in two clinics in Ecuador. Int J Tuberc Lung Dis 2000;4:115-117.

18 Wang PD, Lin RS: Drug-resistant tuberculosis in Taipei, 1996-1999. Am J Infect Control 2001;29:41-47.

19 Girardi E, Antonucci G, Tronci M, Brodi E, Ippolito G: Drug resistance among tuberculosis patients in Rome, 1990-1992. Scand J Infect Dis 1996;28:487-491.

20 Robert J, Trystram D, Truffot-Pernot C, Carbonnelle B, Grosset J: Surveillance of $\mathrm{Myco-}$ bacterium tuberculosis drug resistance in France, 1995-1997. AZAY Mycobacteria Study Group. Int J Tuberc Lung Dis 2000;4: 665-672.

21 Chanteau S, Rasolofo V, Ramarokoto H, Rasolonavalona T, Ratsirahonana O, Ratsitorahina M, Rakotomanana F, Boisier P, Cauchoix B, Auregan G: Anti-tuberculosis drug resistance in Madagascar in 1994-1995. Int J Tuberc Lung Dis 1997;1:405-410.

22 Glynn JR, Jenkins PA, Fine PE, Pönninghaus JM, Sterne JA, Mkandwire PK, Nyasulu S, Bliss L, Warndorff DK: Patterns of initial and acquired antituberculosis drug resistance in Karonga District, Malawi. Lancet 1995;345: 907-910.
23 Carpels G, Fissette K, Limbana V, Van Deun A, Vandenbulcke W, Portales F: Drug resistant tuberculosis in sub-Saharan Africa: An estimation of incidence and cost for the year 2000 . Tuber Lung Dis 1995;76:480-486.

24 Abul AT, Abul HT, Syabbalo NC: Primary drug resistance of Mycobacterium tuberculosis to first line antitubercular agents at Kuwait Chest Diseases Hospital during 1992-1995. Med Principles Pract 1998;7:237-245.

25 Hamze MM, Araj GF: Drug resistance among Mycobacterium tuberculosis isolates in Lebanon. Int J Tuberc Lung Dis 1997:1:314-318.

26 White VLC, Moore-Gillon J: Resource implications of patients with multidrug resistant tuberculosis. Thorax 2000;55:962-963.

27 Tahaoglu K, Torun T, Sevim T, Atac G, Kir A, Karasulu L, Ozmen I, Kapakli N: The treatment of multidrug-resistant tuberculosis in Turkey. N Engl J Med 2001;345:170-174.

28 Weis SE, Slocum PC, Blais FX, King B, Nunn M, Matney GB, Gomez E, Foresman BH: The effect of directly observed therapy on the rates of drug resistance and relapse in tuberculosis. N Engl J Med 1994;330:1179-1184.

29 Helbling P, Altpeter E, Raeber PA, Pfyffer GE, Zellweger JP: Surveillance of antituberculosis drug resistance in Switzerland 1995-1197: The central link. Eur Respir J 2000;16:200-202.

30 Liu Z, Shilkret KL, Finelli L: Epidemiology of drug-resistant tuberculosis in New Jersey from 1991 to 1995 . Int J Epidemiol 1998;27:121126.

31 Riley LW, Arathoon E, Loverde VD: The epidemiologic patterns of drug-resistant Mycobacterium tuberculosis infections: A communitybased study. Am Rev Respir Dis 1989;129: 1282-1285.

32 al Jarad N, Parastatides S, Paul EA, Shelton CD, Gaya H, Rudd RM, Empey DW: Characteristics of patients with drug resistant and drug sensitive tuberculosis in East London between 1984 and 1992. Thorax 1994;49:808810 . 